\title{
THE ARCTIC OCEAN MULTI-YEAR ICE BALANCE, 1979-82
}

\author{
by
}

\author{
D.A. Rothrock and D.R. Thomas
}

(Polar Science Center, Applied Physics Laboratory, College of Ocean and Fishery Sciences, University of Washington, Seattle, WA 98105-6698, U.S.A.)

\section{ABSTRACT}

A method of determining the temporally varying "state" of the ice cover (the concentrations of three surface types: open water, first-year ice, and multi-year ice) is presented. The methodology is that of Kalman smoothing: a physical model and a measurement model are used to blend satellite passive microwave data and buoy data to give an optimal estimate of the ice state. The estimates are optimal only to the degree that model parameter values are known and assumptions about variances are met. Uncertainty about these values and assumptions, and lack of independent data with which to compare results, leaves self-consistency as the most important test of results. A four-year record (1979-82) of the estimated Arctic Ocean ice balance is presented and shown to be self-consistent. Results are discussed in terms of the Arctic multi-year ice balance, which may be an important factor in the interaction of ocean, sea ice and climate because of its relationship to the minimum summer ice extent. The estimated area of multi-year ice decreases each year, but the decrease is small and insignificant based on four years of results. Furthermore, the observed decrease may be due to instrument drift or changes in the multiyear ice signature.

\section{INTRODUCTION}

A substantial temporal record of satellite passive microwave observations of sea ice has been amassed. The multi-channel record began with the Scanning Multichannel Microwave Radiometer (SMMR) in October 1978 and continued with the Special Sensor Microwave Imager (SSM/I) in July 1987. Because of the large difference in brightness temperature between sea ice and ice-free ocean, these data are useful for estimating temporal histories of sea-ice extent, globally and regionally (Gloersen and Campbell, 1988; Parkinson and Cavalieri, 1989).

Algorithms have been developed that utilize the multichannel brightness temperatures to distinguish multi-year ice from first-year ice (e.g. Cavalieri and others, 1984). Multi-year ice is ice that has undergone at least one summer's surface melt and brine drainage, a process that gives it a wintertime microwave signature different from that of first-year ice. The algorithms are unreliable during summer when ice of all ages has the same signature. More recently, Thorndike (1988) and Thomas and Rothrock (1989) have used Kalman filtering and smoothing to demonstrate how time histories of first-year and multi-year ice concentrations can be derived at both Eulerian and Lagrangian points. The method blends microwave data with a physical model describing how the ice cover evolves in time. Here, we extend this approach to an analysis of the ice balance for the Arctic Ocean and include the flux of ice types from one region to another.

Is the area of multi-year ice important? We believe that it is, and that the interaction between sea ice and climate is more complex than the usual assumption of advance and retreat of a nominally uniform ice cover. Consider the sources and sinks of Arctic multi-year ice. The only source of multi-year ice area is the first-year ice that is thick enough to survive summer melt. Three sinks of multi-year ice area can be defined: (1) ridging, (2) export of multi-year ice to melt in the Greenland and Iceland seas, and (3) melt within the Arctic Ocean. Ridging of multi-year ice is probably not significant. Export removes on the order of $10 \%( \pm 5 \%)$ a year of the multi-year ice (Moritz, 1988). The area of multi-year ice in the Arctic Ocean lost to melt is estimated to be about equal to export. We assume that, under present Arctic Ocean ice conditions, multi-year ice area loss is due mostly to lateral melt rather than surface ablation. If the area of first-year ice surviving the summer is approximately equal to the export plus melt of multi-year ice during the year, a reasonably stable annual cycle of the ice cover is possible in spite of large variations in the maximum ice extent. This occurs because the minimum summer ice cover is strongly related to the area of multi-year ice the following fall. Small changes in lateral melt rates or in the length of summer will be reflected in small changes in the area of multi-year ice. However, larger changes in climate, or perhaps persistent small changes, will eventually cause top and bottom ablation to become an important sink of multi-year ice area. In this case the ice cover would evolve toward ice-free summers. Because decreasing summer ice concentration increases melt rates, the state of ice-free summers (and no multi-year ice) is probably easier to enter than to leave (Donn and Shaw, 1966).

An accurate history of the multi-year ice balance and its fluctuations would be useful in understanding the relationship between climate and the multi-year ice balance, as well as providing a baseline for interpreting future changes. A four-year record (1979-82) of the Arctic Ocean ice balance, including area of multi-year ice, is presented here. It is not adequate for determining any long-term trends in the amount of multi-year ice, but we believe the methodology is proved to be well suited to this study. Our results are "seasonally self-consistent", meaning they satisfy some basic assumptions about the ice cover. For instance, the minimum summer ice concentration is approximately equal to the following fall's multi-year ice concentration ("approximately" because new first-year ice may be forming in some locations faster than old ice is melting elsewhere). Future work will extend the analysis in time and space.

\section{PROCEDURE}

The study region, shown in Figure 1, is the Arctic Ocean between Bering Strait and Fram Strait, north of the land masses and major island groups. We assume the only exchange of ice between the Arctic Ocean and marginal seas occurs via Fram Strait, with the Greenland Sea as an unmodeled ice source/sink region. The region is divided into seven cells, and the concentrations of open water, first-year ice, and multi-year ice are computed for each cell on a one-month time step. Cell 6, the central Arctic Basin, consists mostly of the area north of $84^{\circ}$, which is not observed by SMMR.

SMMR data for the period February 1979 through December 1982 are used for the analysis. The SMMR data are the $25 \mathrm{~km}$ gridded values (for every other day) available from NSIDC, Boulder, Colorado. We rotated the ten-channel SMMR data into principal component space (Rothrock and 


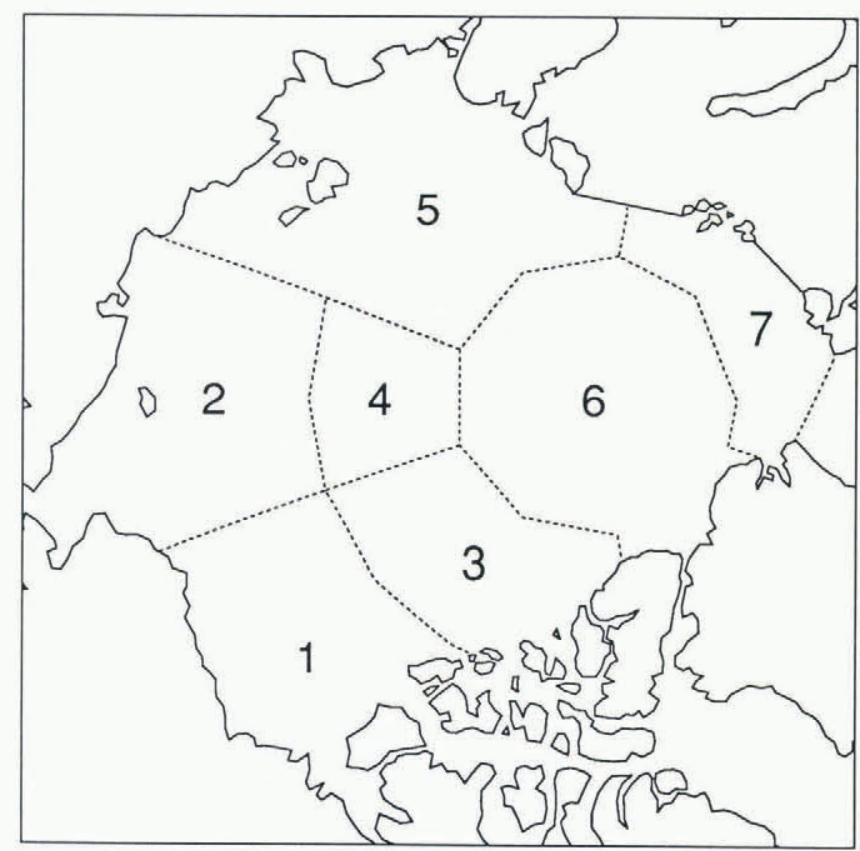

Fig. 1. The Arctic Ocean with the seven computational cells shown.

others, 1988) and used only the first two principal component scores $\left(Z_{1}, Z_{2}\right)$. These two principal components account for about $99 \%$ of the total variance of the ten channels. The data were then averaged within cells and over one-month time periods.

The ice velocities across cell boundaries were interpolated from buoy motion data. Time of freeze-up and the ice melt and growth seasons were determined from surface temperatures. Surface temperature and ice motion are measured by a network of drifting buoys maintained on the Arctic ice since February 1979 (Thorndike and Colony, 1983).

A discrete Kalman filtering/smoothing procedure is used to estimate the ice state - the 21 component vector of the three surface type concentrations for each of the seven cells. The procedure uses a physical model to describe how the ice state $\boldsymbol{X}$ changes with time:

$$
X(n)=\Phi(n \mid n-1) X(n-1)+V(n)
$$

where $X(n)$ is the $(21 \times 1)$ state vector at time $t(n)$, $\Phi(n \mid n-1)$ is the $(21 \times 21)$ transition matrix relating $X(n)$ to $X(n-1)$, and $\boldsymbol{V}(n)$ is a random vector $(21 \times 1)$ representing unmodeled physics and having covariance $Q$.

A measurement model relates the ice state to brightness temperature:

$$
Z(n)=H(n) X(n)+\boldsymbol{U}(n)
$$

where $Z(n)$ is the $(14 \times 1)$ measurement vector, $H(n)$ is a $(14 \times 21)$ matrix of pure type signatures, and $U(n)$ is a measurement error vector $(14 \times 1)$ having covariance $R$.

Further details of the application of Kalman filtering and smoothing to passive microwave observations of sea ice are given in Thorndike (1988) and Thomas and Rothrock (1989). Descriptions of the transition matrix, $\boldsymbol{\Phi}$, and the measurement process, $\boldsymbol{H}$, follow. The description assumes a three-component state vector for each cell. For computation, the multi-year ice concentrations are eliminated from the equations by making use of the fact that $X_{\text {ow }}+X_{\mathrm{fy}}+X_{\mathrm{my}}=1$.

The physical model accounts for ice melt during the summer, growth of open water into first-year ice during the winter, ageing of first-year ice into multi-year ice during fall freeze-up, and advection of ice from one area to another, including advection from the Arctic Ocean into the Greenland Sea. The transition matrix $\Phi$ can best be understood by viewing it as a $(7 \times 7)$ array of $(3 \times 3)$ sub-matrices:

$$
\boldsymbol{\Phi}=\left[\begin{array}{cccc}
\phi(1,1) & \phi(1,2) & \ldots & \phi(1,7) \\
\phi(2,1) & \phi(2,2) & \ldots & \phi(2,7) \\
\cdot & \cdot & & \cdot \\
\phi(7,1) & \phi(7,2) & \ldots & \phi(7,7)
\end{array}\right]
$$

where the diagonal $\phi(i, i)$ represent the processes that can be described without reference to other cells, and the off diagonal $\phi(i, j)$ are the processes that happen in cell $j$ that affect cell $i$. Advection of ice from cell $j$ into cell $i$ is the only such process. Many of the $\phi(\mathrm{i}, \mathrm{j})$ are zero since only adjacent cells can exchange ice.

The transition sub-matrices $\phi(i, i)$, in terms of the physical processes, are

$$
\Phi(i, i)=\left[\begin{array}{ccc}
1-g & m_{1}+d-g d & \mathrm{~m}_{2}+d-g d \\
g & 1-m_{1}-d+g d-a & g d \\
0 & a & 1-m_{2}-d
\end{array}\right]
$$

Physical processes are given as integrals over one time step of a rate. Ice growth $(g)$ is assumed to be 0 during the summer and 1 during the winter except during the first month of winter (freeze-up) when $g$ is 0.5 . We assume $g$ to be 1 during the winter because we have also assumed that the mean consolidated ice signature during the winter represents an ice concentration of 1.0. This is reasonable since ice as thin as $5 \mathrm{~cm}$ has a first-year ice microwave signature, but it should be noted that our results do not resolve a small, but unknown, percentage of open water during the winter. Ageing $(a)$ is equal to 1 at freeze-up and 0 the rest of the year. Summer melt $\left(m_{1}\right.$ and $\left.m_{2}\right)$, unknown parameters in the physical model, are adjusted so that the ice sources and ice sinks roughly balance. Melt rates are assumed to be larger in the peripheral cells $(1,2$, 5 , and 7) than in the central Arctic. First-year and multi-year melt $\left(m_{1}\right.$ and $\left.m_{2}\right)$ of 0.35 and 0.08 are used for cells $1,2,5$, and 7 , and 0.25 and 0.04 for cells 3, 4, and 6. These values are basically guesses, but are of the right order. During the first month of each summer, melt is halved. The lower melt rate at the beginning of summer (and the corresponding lower growth rate at freeze-up) are to account for the time it takes for the seasons to change across our large cells. Advection $(d)$ is the area flux out of cell $i$ to all connecting cells normalized by the area of cell $i$.

The sub-matrices $\phi(i, j)$, for $i \neq j$, are written as

$$
\phi(i, j)=\left[\begin{array}{ccc}
0 & -\sigma c & -\sigma c \\
0 & \sigma c & (\sigma-1) c \\
0 & 0 & c
\end{array}\right]
$$

where $c$ is the area flux from cell $j$ into cell $i$, normalized by the area of cell $i$. The parameter $\sigma$ is 1 during summer and 0 during winter. This parameter allows us to close up open water during a summer convergence event, and ridge (remove an area of) first-year ice during a winter convergence event.

Variations in brightness temperatures due to surface temperature variations are accounted for by computing the "pure type" signatures for each cell as a linear function of surface temperature. The open water signature is, however, assumed to be constant. The measurement error covariance matrix is approximated by $R=r I$, where $r$ is a measure of the variability of the $Z s$ not explained by $\boldsymbol{H}$ or $\boldsymbol{X}$. We set $r=16 K^{2}$ during the winter and $r=400 K^{2}$ during the summer. Having essentially no data for cell 6 we use the SMMR data between $83^{\circ}$ and $84^{\circ} \mathrm{N}$ and set the $(11,11)$ and $(12,12)$ elements of $\boldsymbol{R}$ to $900 K^{2}$ throughout the year. Thus, concentrations for cell 6 are determined almost entirely by the physical model. To a lesser extent this applies to all other cells during the summer.

\section{RESULTS}

Although we compute the state for each of the seven cells, the results discussed here are the concentration for the whole Arctic Ocean. This is just the area-weighted average of the seven cell concentrations. Conversion of concentrations to areas requires multiplication by the total area, $6.9 \times 10^{6} \mathrm{~km}^{2}$. In Figure 2 we show the monthly average concentrations of open water, first-year ice, and 


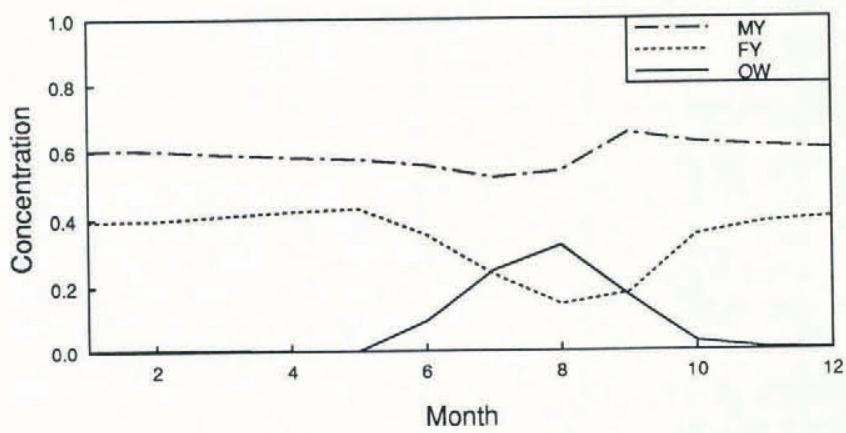

Fig. 2. Monthly average concentration estimates of open water, first-year ice, and multi-year ice for the Arctic Ocean (all seven cells) for the period February 1979December 1982.

multi-year ice. The summer maximum open water concentration is 0.32 on average. Because of variability in the time of freeze-up across the Arctic, and ice export during freeze-up, it is likely that the gross summer open water production is slightly larger than the maximum. This implies that 0.68 , or slightly less, of the post-freeze-up ice cover is multi-year ice. The estimated value is 0.65 , satisfying this elementary but necessary test of consistency.

Figure 3 shows the four annual time histories of multi-year ice concentration. All but one of the 35 12 month-lagged differences show a decrease in multi-year ice concentration, averaging about $0.03 \mathrm{year}^{-1}$. Since the multi-year concentrations are highly correlated from month to month during the ice season, a realistic number of degrees of freedom for the differences is $4-1=3$ (not $35-1=34)$. The annual decrease is not significantly different from zero ( $t$-test for $1-\alpha=0.9$ ). Furthermore, a change in the multi-year ice signature not directly related to surface temperature, or drift in the SMMR instrument, could also account for the observed decrease. SMMR data from regions of first-year ice do not show much interannual variation, but data from regions assumed to be all or mostly multi-year ice do show some interannual variability. These questions need to be resolved, and a longer time period analyzed, before any trend in the multi-year ice concentration can be determined.

How accurate are the concentration estimates? An estimation error covariance is one output of the procedure. The estimation error standard deviations for open water and first-year ice are 0.01 and 0.02 . These error estimates assume that correct values of $\boldsymbol{\Phi}, \boldsymbol{H}, \boldsymbol{Q}$, and $\boldsymbol{R}$ are used. We are sure that some or all of these parameters are in error; the estimation error is more likely a lower bound to the true error. The concentration estimates for the individual cells range from -0.05 to 1.06 ; the maximum error must be at least 0.06 .

A sensitivity study, using the average monthly multiyear ice concentration as the response variable, shows that the pure type signatures $(H)$ are the important parameters to know accurately. Moving the multi-year signature by $10 \%$ of the distance between the first-year and multi-year signatures results in about 0.05 change in $X_{\text {my }}$. The results are insensitive to small errors in the other parameters. Changing the multi-year melt rates by $50 \%$ resulted in less than 0.01 change in $X_{\text {my }}$.

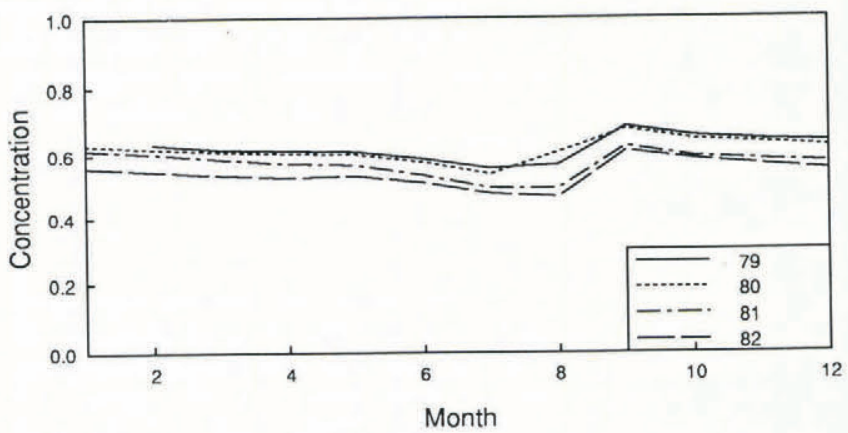

Fig. 3. Four years (1979-82) of Arctic Ocean multi-year ice concentration estimates.

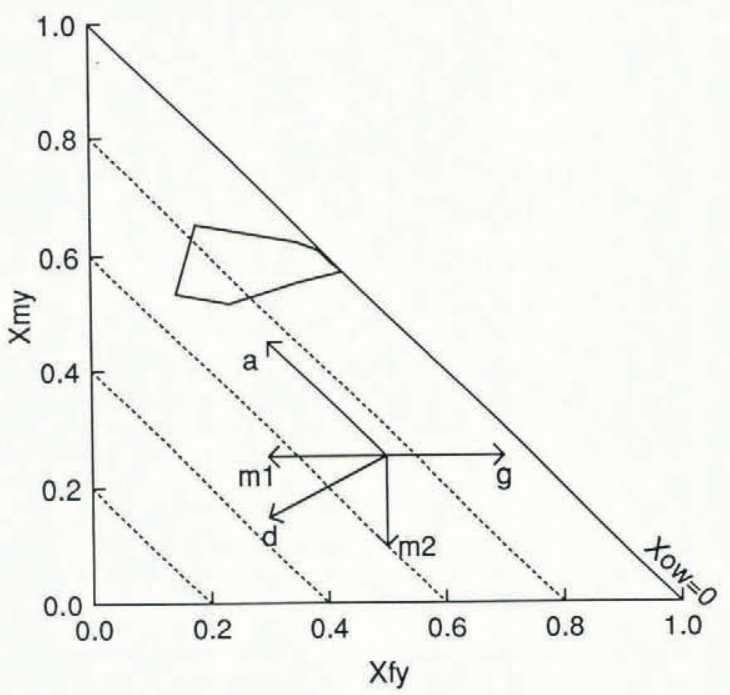

Fig. 4. The four-year average annual cycle from Figure 2 shown as a closed curve in phase space. The dashed line represents the idealized freeze-up process (see text). The vectors (of arbitrary magnitude) show the directions that the modeled physical processes $\Phi$ move an arbitrary state in phase space: ageing $(a)$ converts first-year into multi-year ice, melt $\left(m_{1}\right.$ or $\left.m_{2}\right)$ reduces first-year or multi-year ice, growth $(g)$ converts open water to first-year ice, and divergence $(d)$ removes ice, creating open water. The vector $\boldsymbol{d}$ is shown for a homogeneous ice cover; the actual orientation of $\boldsymbol{d}$ depends on the ice type being advected out of the region. Convergence (not shown) operates in the opposite sense from $d$; ice imported into the region reduces the amount of open water (if any) or first-year ice (through ridging).

Since we do not have independent measurements of concentrations with which to compare our estimates, the best we can do is examine the results for self-consistency. First, we note that the parameter $q$ is chosen to ensure that the estimated concentrations are compatible with the observations according to the criterion defined by Thorndike (1988). Secondly, the notion of seasonal self-consistency is a recognition of limitations on the state evolution due to known physical processes. In particular, the freeze-up process may be approximated by the $\Phi$ matrix with melt $=0$, growth $=1$, and ageing $=1$. For the Arctic Ocean, and a month-long time step, the relationship is only approximate because of both the spatial variability of the date of freeze-up and the advection of ice out of the Arctic during the freeze-up period. Nevertheless, we can say that, for the month just after freeze-up, $X_{\text {ow }}$ is about $0, X_{\mathrm{fy}}$ is slightly larger than $X_{\mathrm{ow}}$ (for the month just before freeze-up), and $X_{\text {my }}$ is slightly less than $1-X_{\text {ow }}$ (just before freeze-up).

The freeze-up, and other physical processes, can be easily visualized in phase space. Since only two of the three surface type concentrations are independent, the phase space is two-dimensional; we chose $X_{\mathrm{my}}$ versus $X_{\mathrm{fy}}$. The third concentration, $X_{\text {ow }}$, can be displayed by contours. In phase space, the state vector consists of a point; evolution of the state over time results in a trajectory. This is illustrated in Figure 4, where the three time histories shown in Figure 2 are shown as the single closed loop. Below the average annual cycle, we show a set of vectors representing the physical processes incorporated in our model. The origin and magnitude of the vectors are arbitrary. The freeze-up process, if we assume it to take place instantaneously, is shown by the dashed line in Figure 4 and is simply the sum of two vectors originating at the summer maximum open water state: one up and to the left along an open water contour to $X_{\mathrm{fy}}=0$ (ageing), the other horizontally right to the $X_{\text {ow }}=0$ contour (growth).

In Figure 5 we show phase space representations of four different estimates of the four-year time history of $X$. Figure 5a shows the results from the Kalman smoothing procedure. We note that the early winter ice concentrations are consistent with the summer maximum open water to 

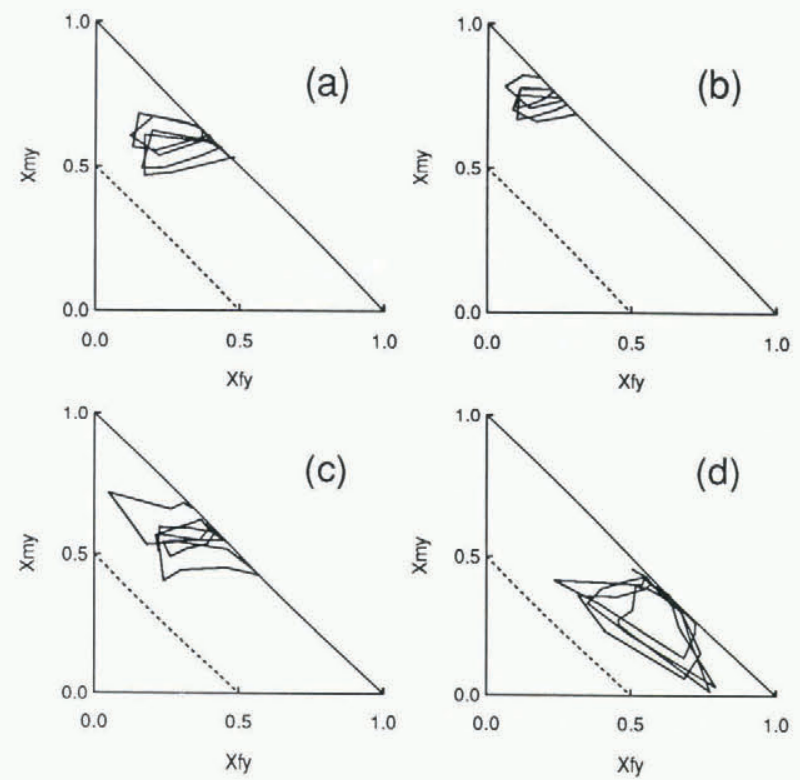

Fig. 5. Four-year cycle of Arctic Ocean ice cover as computed by: (a) the Kalman smoother, (b) the equilibrium solution to the physical model, and (c) the Kalman smoother but assuming that the measurements are much more accurate than the model, and (d) the NASA algorithm.

within a few per cent. Part of the reason for that agreement lies in the physical model which has the agreement built in. We can get some feel for the solution by looking at two other estimates of $X$. Figure 5b shows the equilibrium solution for the physical model. The equilibrium solution is shown so that initial conditions, $X(0)$, have no effect. The results are seasonally self-consistent, but have about $10 \%$ more multi-year ice than the solution in $5 \mathrm{a}$ has. Figure $5 \mathrm{c}$ shows an approximation to the solution $X=$ $H^{-1} Z$, the straightforward inversion of the measurement model. The solution is actually the ouput of the Kalman smoother with $r=0.01 K^{2}$ (very accurate measurements) and $q=1.0$ (the model random input taken to be so large that the model agrees with any $Z$ ). The solution is messy, but the winter multi-year ice is about the same as solution 5a, and the summer open water maximum is roughly consistent with winter first-year ice concentration. Solution $5 \mathrm{c}$ depends only on $\boldsymbol{H}$, the pure type signatures. The messiness probably arises because of deterministic variability in the pure type signatures that we did not include in $\boldsymbol{H}$.

The self-consistency merely means that the summer signatures are consistent with the winter signatures. The comparison of $5 \mathrm{~b}$ with $5 \mathrm{c}$ suggests that either our estimate of $H$ must be off (indicating too little multi-year ice and summer open water in $5 c$ ), or our physical model, $\boldsymbol{\Phi}$, tends to accumulate too much multi-year ice. As a point of reference, we used the NASA algorithm (Gloersen and Cavalieri, 1986), which does not include a physical model, to estimate the $X$ shown in Figure 5d. The algorithm description contains ambiguous information about the tie-points (pure type signatures) used. However, both sets of tie-points give nearly the same results. There is also a sign error in the algorithm description which is corrected for the results in Figure 5d. These results show much less multi-year ice than $5 \mathrm{a}$ or $5 \mathrm{c}$, because different $\mathrm{Hs}$ (pure type signatures) were used. There is also about a 0.20 inconsistency between the summer maximum open water and the winter ice concentrations, indicating an inconsistency between the summer and winter pure type signatures. If our own average pure type signatures are used in the NASA algorithm, the results show about 0.17 more multi-year ice than is shown in $5 \mathrm{~d}$.

\section{CONCLUSIONS}

The Kalman smoothing procedure is a useful method for estimating a temporally varying state of the Arctic ice cover. The absolute accuracy of the method is unknown due to lack of independent data. Calculated estimation errors are small, $1-2 \%$ month $^{-1}$, but depend on the accuracy with which we know several physical parameters, of which we admittedly have imperfect knowledge. However, the results are reasonable, and they satisfy simple tests of seasonal self-consistency. Estimates based on just the physical model, or on just the microwave data, are less reasonable, or possibly inconsistent. A major advantage of the Kalman procedure is that it allows us to relate quantitatively through physical processes, the passive microwave data and independent data such as the ice motion data. Not only does this enhance the value of each data set, but it aids in our understanding of the evolution of the Arctic ice cover.

Our analysis of four years of data suggest a small, steady decrease in the Arctic multi-year ice cover. The decrease is not significant based on four years of data, nor is it certain that the decrease is even real. Future work will include improving estimates of the physical parameters, processing a longer temporal record, and analyzing the area balance of individual cells.

\section{ACKNOWLEDGMENTS}

The SMMR data used in this study were provided by WDC-A for Glaciology/National Snow and Ice Data Center, University of Colorado, Boulder, Colorado 80309-0449. This work was supported by the U.S. National Science Foundation under grant DPP-8832314.

\section{REFERENCES}

Cavalieri, D.J., P. Gloersen, and W.J. Campbell. 1984. Determination of sea ice parameters with the NIMBUS 7 SMMR. J. Geophys. Res., 89(D4), 5355-5369.

Donn, W.L. and D.M. Shaw. 1966. The heat budgets of an ice-free and an ice-covered Arctic Ocean. J. Geophys. Res., 71(4), 1087-1093.

Gloersen, P. and W.J. Campbell. 1988. Variations in the Arctic, Antarctic, and global sea ice covers during $1978-1987$ as observed with the Nimbus 7 scanning multichannel microwave radiometer. J. Geophys. Res., 93(C9), 10,666-10,674.

Gloersen, P. and D.J. Cavalieri. 1986. Reduction of weather effects in the calculation of sea ice concentration from microwave radiances. J. Geophys. Res., 91(C3), 3913-3919.

Moritz, R.E. Unpublished. Ice budget of the Greenland Sea. (Ph.D. dissertation, Yale University, 1988.)

Parkinson, C. and D.J. Cavalieri. 1989. Arctic sea ice 1973-1987: seasonal, regional, and interannual variability. J. Geophys. Res., 94(C10), 14,499-14,523.

Rothrock, D.A., D.R. Thomas, and A.S. Thorndike. 1988. Principal component analysis of satellite passive microwave data over sea ice. J. Geophys. Res., 93(C3), 2321-2332.

Thomas, D.R. and D.A. Rothrock. 1989. Blending sequential SMMR and buoy data into a sea ice model. J. Geophys. Res., 94(C8), 10,907-10,920.

Thorndike, A.S. 1988. A naive zero-dimensional sea ice model. J. Geophys. Res., 93(C5), 5093-5099.

Thorndike, A.S. and R. Colony. 1983. Objective analysis of atmospheric pressure and sea ice motion over the Arctic Ocean. In POAC 83. The Seventh International Conference on Port and Ocean Engineering under Arctic Conditions, Helsinki, Finland, 5-9 April 1983. Volume 2. Espoo, Technical Research Centre of Finland, 1070-1079. 